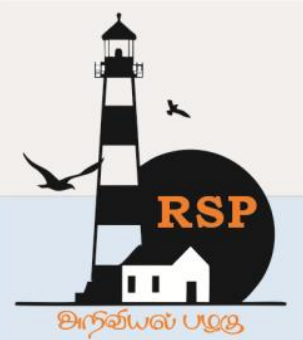

INTERNATIONAL RESEARCH JOURNAL ON ADVANCED SCIENCE HUB

RSP SCIENCE HUB

(The Hub of Research Ideas)

Available online at www.rspsciencehub.com

Special Issue of First International Conference on Science, Technology \& Management (ICSTM-2020)

\title{
Rediscovery of handloom cluster with reference to sustainability and empowerment
}

Shangrella M K Rajesh ${ }^{l}$

${ }^{1}$ Assistant Professor, Department Fashion Design, National Institute of Fashion Technology, Kannur. shangsrajkrishna@gmail.com ${ }^{1}$

\begin{abstract}
This study concentrates on natural dyeing methods to contribute to the sustainability phenomenon, which is a buzzword in the fashion industry now. Kerala being a state where jack tree is abundantly available any time of the year, this study proposes to revive this cluster by training these women with the sustainable and innovative dyeing technique of jack bark dyeing. The jack tree, a major source of natural dye, has a potential demand in the international market. Today people around the globe are rediscovering color using renewable and non - toxic natural sources. Now-a-days, people are becoming health conscious, and are going organic, herbal, or natural. Although there is an affinity towards organic food, organic textiles, herbal cosmetics/medicines, the knowledge about natural dyes and application of natural dyes is minimal. Bark wood of jack tree is first made into chips, sawdust or even powdered. In order to survive in this competitive world, this all women cluster needs to be innovative and creative in what they produce. To keep the handloom tradition with natural tint in it, this jack tree dye recipe will play the major role.
\end{abstract}

Keywords: Eco Fashion, Sustainable Practices, Handloom Cluster, Women Empowerment, Jack Tree Bark.

\section{Introduction}

As the only means of colouring textiles, the enormous importance of natural dyes remained unchallenged until the mid-19th century, when William Perkin, fifteen years old, discovered the first synthetic dye. He produced a reddish-purple dye out of a coal tar derivative. 'Perkin's Mauve' had a huge effect on the fashion world of the day, especially after Queen Victoria appeared at the Great Exhibition of 1862 wearing this new colour. The subsequent growth of many more synthetic colours. The demise of natural dyeing on an industrial scale is witnessed by the subsequent development of many more synthetic colors, representing a cheaper and more convenient way of dyeing fabric. After the advent of chemical dyes in the awareness and practice of natural dyeing, the supply of natural dyes has decreased significantly for various reasons, including convenience, color preference, and environmental problems. In many respects, India is a rich country. On one hand, it maintained its conventional wisdom and continued on the other with creativity, exploration, search, study, and scientific testing. India has a rich cultural heritage that has formed an integral part of the art of hand weaving and natural dyeing. The tradition of hand weaving has existed in India for more than five thousand and eight hundred years. There are several references to the glory of the Indian handloom in the very early Indian religious texts. There are many instances that illustrate that many abroad in the East and West patronized Indian handloom cloths in those days. On Indian fabric, Herodotus of Greece and scholars like Magasthanese and Pliny wrote about all this. Among the hundreds of small-scale and cottage arts and crafts that have survived currently, handloom weaving is perhaps India's most significant and important craft. With over 30.22 lakh looms spread over the entire length and 
breadth, it is the largest cottage industry. Synthetic dyes are made from chemicals isolated from petroleum derivatives at a high temperature and pressure. Many carcinogenic chemicals are used during the production phase of dyes, which contributes to the creation of toxic by-products. In rivers, ponds or left in the open, these by-products are discharged. Therefore, water and atmospheric emissions cause serious pollution. Dying and handling textiles is the world's second-largest polluter, usurped only by agriculture. In a survey, the World Bank reported that up to one-fifth of industrial water contamination is caused by textile production worldwide, with the release of as many as 72 toxic chemicals hitting the water supply. Nevertheless, among other factors, increasing raw materials and labor costs have created a demand for something cheaper, simpler and safer in textile production. Nearly all the criteria are fulfilled by natural dyes; with advantages, mainstream manufacturers have only just begun to accept them. Therefore, this jack tree bark dyeing will have an excellent potential in the apparel market.[1-4]

\section{Background}

The dyeing of natural dyes was one of the oldest methods of ancient civilization. This is evident from the wall paintings of Ajanta, Ellora, Sithannavasal, Mithila, and Egyptian pyramids that were primarily made with natural colorants. The ancient craftsmen colored indigo in the form of blue, turmeric and saffron yellow, acacia brown and lake red, safflower and madder. Thus, for centuries, natural dyeing has been an important part of human life. According to the Buddhist rules set out in the book of discipline of the monk, their robes must be dyed and produced naturally. Early Buddhist religious authorities interpreted the instructions for the color of the robe to be colored between yellow and red when made. Due to the various indigenous plants used to dye them, Buddhist sects around the world have various colored robes. For instance, Buddhist monks use the dull yellow color often used on the streets of Bangkok, and in Thailand, because it is a tone achieved from the heartwood of the indigenous Jackfruit tree.

Kerala is a small strip of land situated between Arabian Sea and Western Ghats at the south West corner of India. Kerala is a green state and a wide range of trees and plants exist. Various species of trees occur and some of them are cultivated for fruit. For this analysis here which is widely known as; Common Name: Plavu (Jackfruit tree) Scientific Name: Artocarpus heterophyllus, one of the major fruit-giving tree of Kerala is taken. In the treatment of various diseases such as vitiated vata, pitta, diarrhea, skin disease, urinary retention and general weakness, the Jackfruit tree is used. As it is termite-proof, the tree's timber is used for making furniture.

The jack fruit tree is a large evergreen tree considered the world's largest tree-borne fruit. Based on the results of vankar et al. (2016), the current study was undertook in the state of Kerala, a region with abundant jack trees available perennially the bark is easily available throughout the year in Kerala. The traditional handloom sector of Kerala is spread through most parts of the district. The total number of households involved in the district is 745 , of which 525 are in the cooperative sector, 140 in the hanveev sector and 80 are private weavers. The total number of registered handloom members in the district's fourteen operating cooperatives is 3673 . Almost 20 per cent of all looms are currently running. The wealth and richness of Indian culture in fabrics is shown by handloom. Over the ages, handloom has been synonymous with the quality of fabric weaver artistry. Kerala's culture and tradition are displayed in handloom products such as set mundu, thorthu, dhothi, sarees, etc. Kerala handlooms are very popular with set mundu and thorthu produced in the palakkad district. This is a study proposed to be undertaken in the kozhinjampara-weaving mill, chittoor, palakkad in the state of Kerala. This allwomen cluster employs 24 weavers who are highly motivated to come up with innovative dyeing practices.[5-8]

The subject of empowerment of women has becoming a burning issue all over the world including India since last few decades. Women empowerment refers to increasing and improving the social, economic, political and legal strength of the women, to ensure equal-right to women. Women empowerment helps women to get benefits from resources, assets, income and their own time, as well as the ability to manage risk and improve their economic status and wellbeing. This study concentrates on natural dyeing methods to 
contribute to the sustainability phenomenon, sustainable fashion, also called eco fashion, is a part of the growing design philosophy and trend of sustainability, the goal of which is to create a system that can be supported indefinitely in terms of human impact on the environment and social responsibility. It can be an alternative trend against fast fashion.

\section{Research highlights}

- The paper focus on dye derived from natural sources, which can be emerged as an important alternative to synthetic dyes.

- The research fulfills the need for developing better solid-liquid extraction techniques for leaching natural colorants from plant materials for applications in dyeing industries.

- This novel technique can be employed effectively for the extraction of coloring matter from the bark of the jack tree

- This process provides effective utilization of natural resources as eco-friendly method in current situation of global environmental concern.

- This natural dye will enhance the structure of kozhinjampara weaving mill, Chittoor, handloom cluster.

- This study will raise the income level of the women weavers as well as to find out the problems and prospect of the all-women handloom cluster.

\section{Material and methods}

Dyes derived from natural sources that have emerged as an effective alternative to synthetic dyes are the focus of attention. There is a potential demand in the international market for the jack tree, a significant source of natural dye. Today, with the use of green and non-toxic natural sources, people around the world are rediscovering color. Kerala being a state where jack tree is abundantly available any time of the year, from the sawdust of jack wood or chips of the heartwood, boiled with alum, is derived a rich yellow/orange dye. To achieve a dull yellow, the jack-wood tree is cut into slices and boiled in water until the solution is dark brown in color. The wetted robe is then placed in the second solution, and left there until the desired 'dirty' yellow pigment is achieved.

\subsection{Extraction of the bark of artocarpus heterophyllus (jackfruit tree)}

A big question faced by the wood converting industries is what to do with bark. Debarking is the method by which bark is extracted from wood. During powerful tornadoes, debarking can occur naturally. Usually, debarking requires the use of industrial equipment onto which the log or stake is mounted. These machines may be either portable or stationary. Generally, they are powered by hydraulic motors, but a power take-off can also drive them. To ensure the removal of bark from all around the log, the log or stake is then pressed against blades or knives that extract the bark when the $\log$ is turned. While this may be very timeconsuming and may not be sufficient for large quantities, debarking may also take place by hand.

\subsection{Prepare the dye bath}

After the bark is removed from the cut log, the dye components chop the bark material into small pieces and put the chopped pieces in the pot. Add twice the amount of water to the substance from the bark. Get it to a boil, and then simmer for an hour or so. Strain and return the dye to the pot and stain the substance without additives or solvents being applied. By adding mixtures of natural dyestuffs to different combinations of iron- and alum-mordents, a large variety in shade and color depth can be achieved. More than $60 \%$ of the dyeing tested achieved reasonable stability properties.

\subsection{Prepare the fabric/yarn with a fixative}

Before the dye process, soak the fabric in a color fixative in order to get the fabric ready for the dye bath. The color set in the fabric is rendered this way. You ought to use a vinegar fixative when using a dye on the fabric/yarn. Combine one part of the vinegar and four parts of the bath, and then boil the fabric for one hour in the mixture. Rinse it out under cold water after an hour when the fabric is finished.

\subsection{Dye the fabric/yarn}

Simmer together in the dye bath and alum (modarnts) with wet fabric/yarn until the desired color is obtained. Enable the material to soak in the dye overnight for a better hue. Then, separately wash the fabric and place it to dry. When it dries, the hue of the fabric becomes brighter.

\section{Discussion}


www.rspsciencehub.com

A visit to the cluster was made during the study where it was discovered that the income of women weavers are very poor and that is because of fewer orders and the competitive level in the industry, orders were not achieved in their cluster and one of the key reasons for this is the lack of creativity in their products. In this Handloom cluster, the cheapest and simplest way to enter the market is to carry something revolutionary and for that, this jack tree bark dyeing was the perfect solution for the time being as natural dyes have a potential market. The market for natural dyes is growing day by day in the modern world. Among the minor dye-yielding plants used in India is the bark of the jackfruit tree (Artocarpus heterophyllus), from which a yellow/orange dye is obtained. Via colour measurements and standard wash fastness checks, the dyeing was assessed. The mordanting method, which has been known for many centuries and linked to textile dyeing, has generally resulted in improved dye absorption and fastness properties for cotton samples, as it is concluded from the tests Fig.6. the Textile committee report.

\section{Limitations}

1. Jack tree bark was not identified based on the best dye yielding barks.

2. The jack tree log that was available at the timber vendor was debarked and the bark was collected for dyeing.

3. At present the Chittoor cluster does not have a dyeing unit to proceed the dyeing activities in large scale.

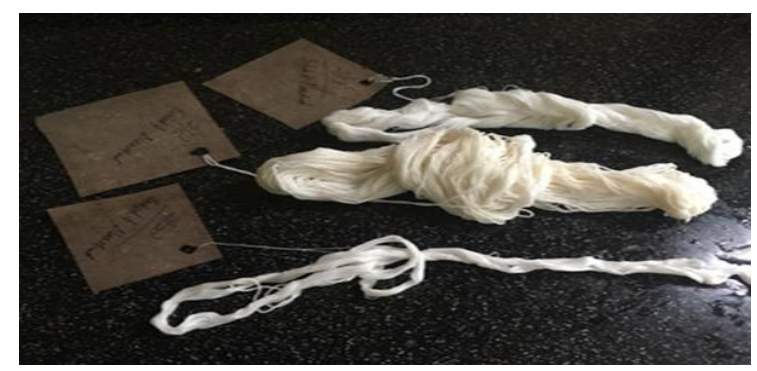

Fig.1: Barks used in dyeing.

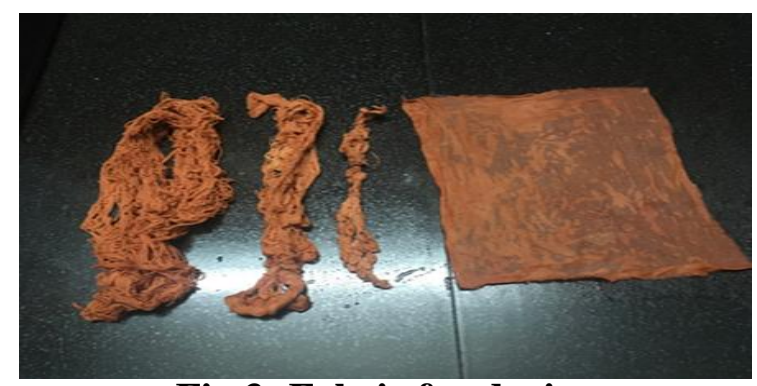

Fig.3: Fabric for dyeing

\section{Scope for further research}

By implementing different novel jack tree bark extraction techniques, the analysis can be improvised. Several natural dye extraction methodologies that satisfy both customer preference and regulatory control and are costeffective. Some of the natural dye extraction techniques are:

- Simple Aqueous Methods

- Complicated Solvent Systems

- Supercritical Fluid Extraction

- Ultrasonic Extraction

There is very little research and development work on the standardization of natural dyes. There have been very few significant attempts at producing new knowledge on the use of natural dyes. Some businesses, such as Alps Industries Ltd, contribute to the standardization of natural dyes. For Textiles, the standardized natural extracts are very useful; the uses of natural dyes are mostly correlated with the term of fastness properties, primarily washing and light fastness. Through careful selection of natural mordents and extraction, along with the best application of technology and ecological processes, this can be enhanced. In the textile industry for eco-friendly textiles, natural dyeing of textiles by industrial processes in large-scale dyeing units is now a reality.

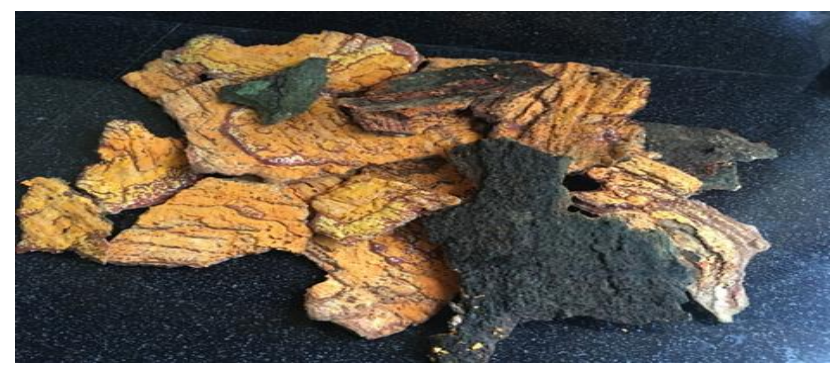

Fig.2: Selected yarns

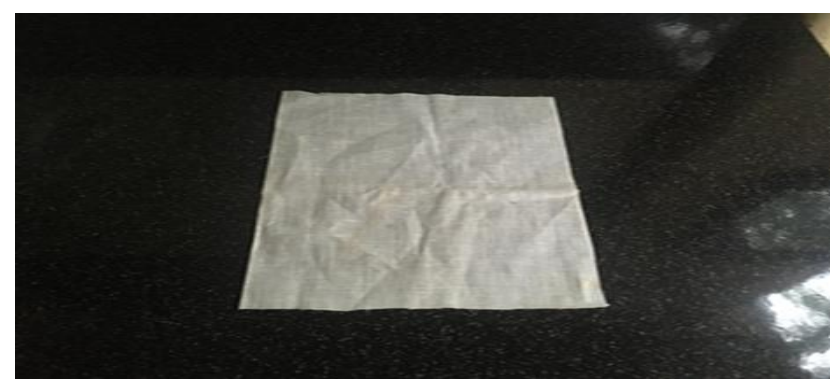

Fig4: Dyed wet samples. 


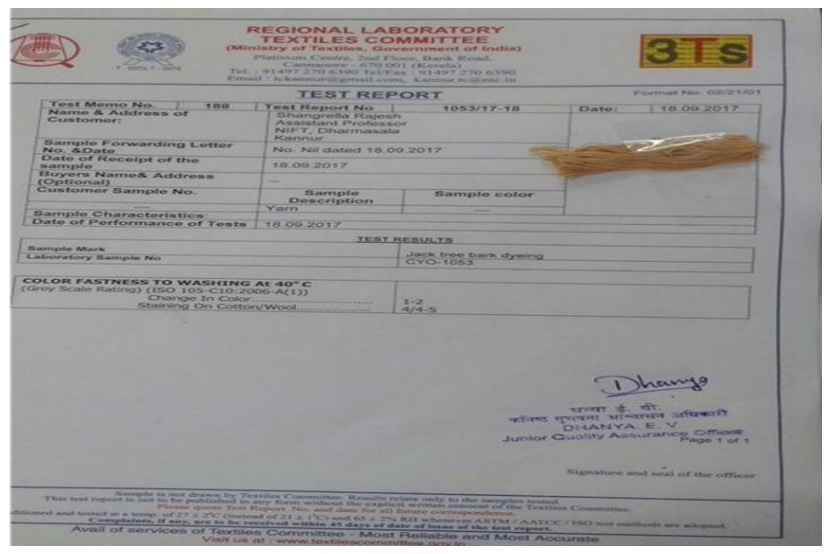

Fig.5: Textile committee report.

\section{Conclusion}

The problems were identified with respect to suboptimal pre-weaving processes including dyeing and weaving technology. In next planned workshop, this study of Jack tree bark dye will be introduced to the cluster for new product development. The Chittoor cluster mainly produce Kerala cotton sarees and the jack tree bark dye will be an innovation to the usual Kerala sarees.Natural dyes has greater biodegradability and higher environmental compatibility in general. They are non-toxic, non-allergic and non-carcinogenic as they are derived without chemical processes from animals, fruits, plants and trees and their bark materials. In conjunction with mordents that have affinity for both coloring matter and fiber, natural dyes are normally used so they form an insoluble precipitate on the fabric by mixing them with the dye. Different colors and tones can be obtained from a single dye source with the aid of mordents. Global awareness of the use of natural resources to save the atmosphere and the planet from pollution and environmental imbalances has also been created. Therefore, the overwhelming variety of natural resources of color pigments is an urge to be used.

\section{References}

[1].Agyarko K, Darteh E and Berlinger B, Metal levels in some refuse dump soils and plants in Ghana, Plant Soil ring., 56 (5), 244- 251, 2010
[2].Alissa E M and Ferns G A, significant metal poisoning and disorder, J. Toxicol., 2011, 21 pages, 2011.

[3]. Christiana Omono M A and Samuel K, Investigation of significant metal levels in road facet agriculture soil and plant samples in Adogo, Nigeria, Academic J. Environ. Sci., 1(2), 31-35, 2013.

[4].Feleafel M N and Mirdal Z M, Hazards and effects of pollution by Lead on vegetable crops, J. Agric. Environ. Ethics, 26(3), 547567, 2013.

[5].Lokeshwari $\mathrm{H}$ and Chandrappa $\mathrm{G} \mathrm{T}$, Impact of significant metal contamination of Bellandur Lake on soil and cultivated vegetation, Current Sci., 91(5), 622-27, 2015.

[6].Singh V P, Metal Toxicity and Tolerance in Plants and Animals, Sarup \& Sons, 2006.

[7].Sattar M U, Khan M A, Khalil A A and ruler $\mathrm{R} M$, Mitigation of significant metals in vegetables through laundry with house hold chemicals, Int. J. Agric. Sci. Res. (IJASR), 3(5), 1-12, 2016.

[8]. Yadav A, Yadav $\mathrm{P} \mathrm{K}$ and Shukh D N, Investigation of significant metal standing in soil and vegetables big in geographic region of Allahabad, Uttarpradesh, India, Int. J. Sci. Res. Publ., 3(a), 1-7, 2017. 